University of Nebraska - Lincoln

DigitalCommons@University of Nebraska - Lincoln

Athletic Performance Research

Athletics

$12-2015$

\title{
Glucose-fructose likely improves gastrointestinal comfort and endurance running performance relative to glucose-only
}

P. B. Wilson

University of Nebraska-Lincoln, pwilson@huskers.com

S. J, Ingraham

University of Minnesota, Minneapolis

Follow this and additional works at: http://digitalcommons.unl.edu/athleticresearch

Part of the Bioinformatics Commons, Biomechanics Commons, Biophysics Commons, Exercise $\underline{\text { Science Commons, Motor Control Commons, and the Psychology of Movement Commons }}$

Wilson, P. B. and Ingraham, S. J,, "Glucose-fructose likely improves gastrointestinal comfort and endurance running performance relative to glucose-only" (2015). Athletic Performance Research. 1.

http://digitalcommons.unl.edu/athleticresearch/1

This Article is brought to you for free and open access by the Athletics at DigitalCommons@University of Nebraska - Lincoln. It has been accepted for inclusion in Athletic Performance Research by an authorized administrator of DigitalCommons@University of Nebraska - Lincoln. 


\title{
Glucose-fructose likely improves gastrointestinal comfort and endurance running performance relative to glucose-only
}

\author{
P. B. Wilson, ${ }^{1,2}$ and S. J. Ingraham ${ }^{2}$ \\ 1 Nebraska Athletic Performance Laboratory, University of Nebraska-Lincoln, Lincoln, NE, USA, \\ 2 Human and Sports Performance Laboratory, School of Kinesiology, University of Minnesota, Minneapolis, MN, USA \\ Corresponding author - P. B. Wilson, Nebraska Athletic Performance Laboratory, University of Nebraska-Lincoln, One Memorial Stadium, \\ Lincoln, NE 68588, USA. Tel: 402472 3490, Fax: 402472 5594, E-mail: pwilson@huskers.com
}

\begin{abstract}
This study aimed to determine whether glucose-fructose (GF) ingestion, relative to glucose-only, would alter performance, metabolism, gastrointestinal (GI) symptoms, and psychological affect during prolonged running. On two occasions, 20 runners (14 men) completed a 120-min submaximal run followed by a 4-mile time trial (TT). Participants consumed glucose-only (G) or GF (1.2:1 ratio) beverages, which supplied $\sim 1.3 \mathrm{~g} / \mathrm{min}$ of carbohydrate. Substrate use, blood lactate, psychological affect [Feeling Scale (FS)], and GI distress were measured. Differences between conditions were assessed using magnitude-based inferential statistics. Participants completed the TT $1.9 \%(-1.9 ;-4.2,0.4)$ faster with GF, representing a likely benefit. FS ratings were possibly higher and GI symptoms were possibly-tolikely lower with GF during the submaximal period and TT. Effect sizes for GI distress and FS ratings were relatively small (Cohen's $d=$ $\sim 0.2$ to 0.4 ). GF resulted in possibly higher fat oxidation during the submaximal period. No clear differences in lactate were observed. In conclusion, GF ingestion - compared with glucose-only - likely improves TT performance after $2 \mathrm{~h}$ of submaximal running, and GI distress and psychological affect are likely mechanisms. These results apply to runners consuming fluid at $500-600 \mathrm{~mL} / \mathrm{h}$ and carbohydrate at $1.0-1.3 \mathrm{~g} / \mathrm{min}$ during running at $60-70 \% \mathrm{VO}_{2 \text { peak }}$.
\end{abstract}

Keywords: endurance, exercise, exogenous, nutrition

When consuming a high rate of carbohydrate $(>60 \mathrm{~g} / \mathrm{h})$ during prolonged exercise, co-ingesting glucose and fructose has been purported to increase exogenous carbohydrate utilization, reduce gastrointestinal (GI) distress, and enhance performance (Jeukendrup, 2010). Glucose and fructose utilize separate transporters for intestinal absorption (SGLT1 and GLUT5; Wood \& Trayhurn, 2003) and have been referred to in the literature as multiple transportable carbohydrates (MTC). When glucose is consumed at a rate above $60 \mathrm{~g} / \mathrm{h}$, SGLT1 may become saturated, providing a plausible mechanism for improvements in exogenous carbohydrate oxidation and GI distress (Jeukendrup, 2010). In addition, fructose ingestion increases blood lactate through up-regulation of pyruvate kinase (Macdonald et al., 1978), and this lactate can be oxidized during exercise (Miller et al., 2002). Furthermore, concentrated fructose solutions empty faster from the stomach than glucose solutions (Sole \& Noakes, 1989) and may result in more rapid fluid delivery (Jeukendrup \& Moseley, 2010; Roberts et al., 2014). These mechanisms provide strong rationale for use of MTC during prolonged exercise, which is supported by studies demonstrating MTC reduce GI distress (O'Brien \& Rowlands, 2011; O'Brien et al., 2013; Roberts et al., 2014) and lead to performance improvements as large as 8\% (Jeukendrup, 2010; Triplett et al., 2010).
Despite these findings, several limitations to the MTC research need to be addressed. Cycling has been used in all but three studies (Pfeiffer et al., 2009; Clarke et al., 2012; Lee et al., 2014), which is unfortunate given the popularity of running and GI distress is more prevalent during running (Peters et al., 1993). None of the three studies that utilized running demonstrated clear benefits with MTC, but they may have been either too short (Pfeiffer et al., 2009; Lee et al., 2014) or did not feed a high enough rate of carbohydrate (Clarke et al., 2012; Lee et al., 2014). Only two studies provided information on beverage flavor characteristics, both of which reported sweetness differences (Rowlands et al., 2008; O'Brien et al., 2013). Furthermore, previous investigations (Jeukendrup \& Moseley, 2010; Lecoultre et al., 2010; Triplett et al., 2010; O'Brien \& Rowlands, 2011; Roberts et al., 2014) often used fluid volumes $(\sim 1000 \mathrm{~mL} / \mathrm{h})$ exceeding ad libitum intakes for field events (Pfeiffer et al., 2012), which suggests these protocols could be difficult to implement during "real-life" events. Finally, studies were often conducted with participants fasted (Jeukendrup \& Moseley, 2010; Lecoultre et al., 2010; Triplett et al., 2010; O’Brien \& Rowlands, 2011; Roberts et al., 2014) and only three studies included women (Pfeiffer et al., 2009; Rowlands et al., 2012; Lee et al., 2014). 
This study aimed to determine whether ingestion of a glucose-fructose beverage, under fed conditions, would alter performance, metabolism, GI symptoms, and psychological affect during prolonged running. Beverages supplied carbohydrate at $1.3 \mathrm{~g} / \mathrm{min}$ in a double-blind, crossover fashion, with goals of matching sweetness and providing realistic fluid and carbohydrate feeding rates. Beverages supplied carbohydrate as glucose-fructose or glucose-only during 120 min of steady-state running, which was followed by a 4-mile time trial (TT). We hypothesized that glucose-fructose ingestion would improve performance, improve psychological affect, reduce GI distress, increase blood lactate, and increase end-exercise carbohydrate oxidation.

\section{Materials and methods}

\section{Participants}

Participants were recruited from the Minneapolis-St. Paul area. Eligibility criteria included completion of at least one marathon within the past year (men < $210 \mathrm{~min}$; women $<225 \mathrm{~min}$ ), running $\geq 30$ miles/week, and completion of at least two 20 -mile runs over the past 2 months. Participants went through an informed consent process prior to signing a University of Minnesota Institutional Review Board approved consent form. A total of 17 men and nine women were enrolled in the study. Fourteen men [35.8 \pm 2.2 years; body mass index (BMI), $22.9 \pm 0.5 \mathrm{~kg} / \mathrm{m}$; personal record marathon time, $182 \pm 2 \mathrm{~min} ; \mathrm{VO}_{2 \text { peak }}, 58.7 \pm 1.9 \mathrm{~mL} / \mathrm{kg} / \mathrm{min}$ ] and six women ( $31.3 \pm 2.9$ years; BMI, $21.8 \pm 0.5 \mathrm{~kg} / \mathrm{m}$; PR marathon time, $201 \pm 6$ min; $\mathrm{VO}_{2 \text { peak }}, 55.0 \pm 2.4 \mathrm{~mL} / \mathrm{kg} / \mathrm{min}$ ) completed all visits; reasons for not completing are presented in Fig. 1.

\section{Procedures}

Each participant underwent two, $\sim 2.5 \mathrm{~h}$ runs during which they consumed the beverages. The initial 120 min consisted of submaximal running at a constant velocity, after which participants completed a 4-mile TT to assess performance. Data collection began October 2013 and was completed by March 2014.
Participants were assigned to beverages using a randomized, double-blind, counterbalanced, crossover design. Beverages supplied carbohydrate at $\sim 1.3 \mathrm{~g} / \mathrm{min}$ during the submaximal period, since a rate of $<0.8-1.0 \mathrm{~g} / \mathrm{min}$ has failed to elicit metabolic and performance differences in past research (Jeukendrup, 2010). Although we considered standardizing the carbohydrate feeding rate to body size, we decided against this since there is little evidence to suggest that carbohydrate absorption capacity is significantly influenced by body size. In addition, fluid volume was not standardized against body size since it would have resulted in different beverage concentrations between participants.

The glucose-fructose beverage (GF) was a $10.3 \%$ carbohydrate mixture (103 g per $1 \mathrm{~kg}$ tap water) containing maltodextrin (StarDri $® 10$, Tate \& Lyle, Decatur, Illinois, USA) and crystalline fructose (Krystar® 300, Tate \& Lyle). Glucose and fructose were supplied in a $1.2: 1$ ratio (5.61\% maltodextrin and $4.66 \%$ fructose) because previous studies have indicated it may be optimal (Rowlands et al., 2008; O'Brien \& Rowlands, 2011; O'Brien et al., 2013). The glucose-only beverage $(\mathrm{G})$ supplied carbohydrate as $5.61 \%$ maltodextrin (Star-Dri ${ }^{\circledR} 10$, Tate \& Lyle) and 4.66\% dextrose anhydrous (Cerelose $\AA$, Ingredion, Westchester, Illinois, USA). Concentrations of $10.3 \%$ were chosen because fluid intakes for runners during events lasting 1-3 h rarely exceed $600 \mathrm{~mL} / \mathrm{h}$ (Pfeiffer et al., 2012), and $1000 \mathrm{~mL} / \mathrm{h}$ of a $6 \%$ beverage would be necessary to supply carbohydrate at $\geq 1.0 \mathrm{~g} / \mathrm{min}$. Both beverages contained sodium chloride (540 mg/kg water) and lemon juice ( $9 \mathrm{~g} / \mathrm{kg}$ water), and since fructose is sweeter than glucose, $\mathrm{G}$ was treated with aspartame ( $90 \mathrm{mg} / \mathrm{kg}$ water). To ensure researcher blinding, one investigator mixed beverages in two identical containers, labeled them, and left the room. An individual not involved with data collection subsequently chose one of the beverages by drawing assignments from sex-specific envelopes.

Participants reported to the Human and Sport Performance Laboratory (HSPL) 1-4 weeks before their first run. Participants completed a cardiorespiratory test on a treadmill (Pro XL, Woodway USA, Waukesha, Wisconsin, USA). The protocol began with a 3 -min walk at $5.0 \mathrm{~km} / \mathrm{h}$ and $0 \%$ grade. Subsequently, 1 -min stages at $1 \%$ grade with $0.64 \mathrm{~km} / \mathrm{h}$ speed increases were used to achieve a speed equal to the participant's $5 \mathrm{~km}$ pace by the 11 th

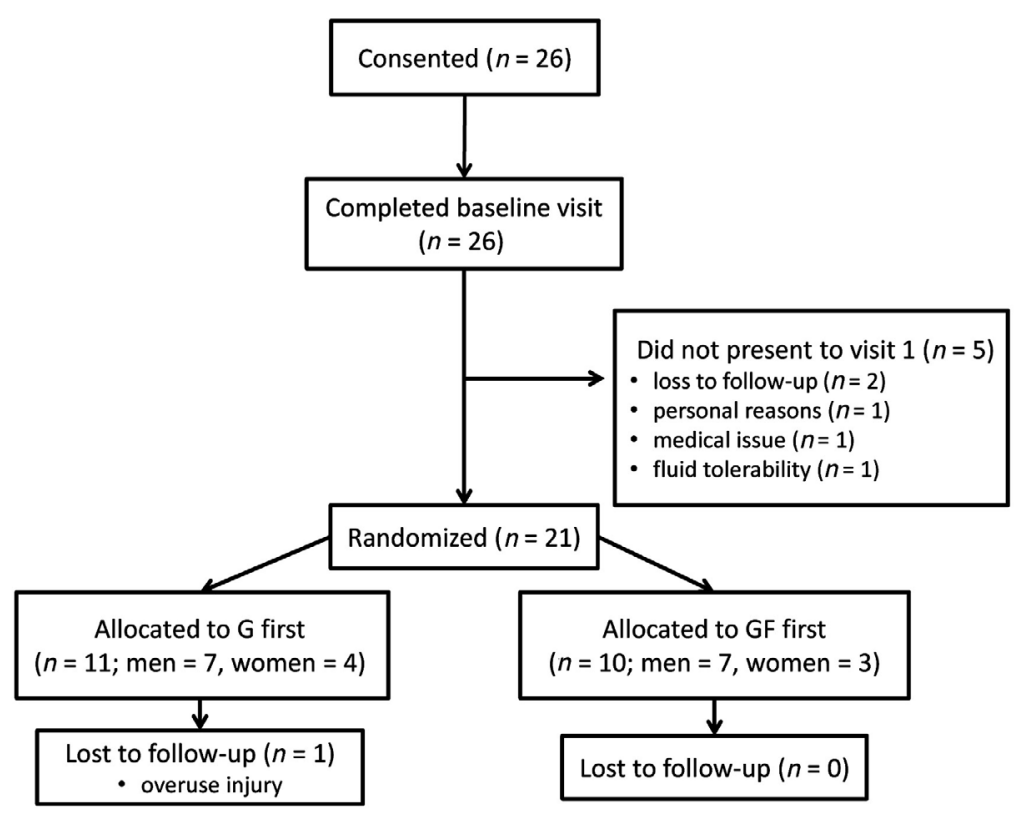

Figure 1. The flow of participants through the study. 
minute. Grade was increased $1.5 \%$ every minute thereafter until volitional exhaustion.

Participants recorded training for 5 days prior to each run, while diet was recorded with prospective records for 2 days. Intakes of energy, carbohydrate, fat and protein were calculated based on manufacturer information (if available) or the USDA Food Database (U.S. Department of Agriculture, 2012). Participants were asked to avoid strenuous activity and alcohol for $48 \mathrm{~h}$ and caffeine for $12 \mathrm{~h}$ before visits. For their second run, participants were instructed to match training and diet from their first run. To further standardize nutrition, participants were supplied meals for the night before (between 5-7 p.m.) and morning of runs ( $2 \mathrm{~h}$ before). The meals provided were between $140-210$ and 75-115 g of carbohydrate for dinner and breakfast, depending on body mass.

\section{Physiological outcomes}

A metabolic cart (Ultima, Medical Graphics, St. Paul, Minnesota, USA) measured breath-by-breath exchange of oxygen and carbon dioxide. Oxygen consumption $\left(\mathrm{VO}_{2}\right)$ and carbon dioxide expiration $\left(\mathrm{VCO}_{2}\right)$ were calculated automatically by the software Breeze (Medical Graphics). Rates of carbohydrate and fat oxidation were estimated using stoichiometric equations from Jeukendrup and Wallis (2005): (carbohydrate $=4.210 \mathrm{VCO}_{2}-2.962 \mathrm{VO}_{2}-2.37 \mathrm{~N}$; fat $=$ $1.695 \mathrm{VO}_{2}-1.701 \mathrm{VCO}_{2}-1.77 \mathrm{~N}$ ). $\mathrm{VCO}_{2}$ and $\mathrm{VO}_{2}$ were in $\mathrm{L} / \mathrm{min}$ and $\mathrm{N}$ (nitrogen excretion) was considered to be negligible.

Capillary blood lactate was assessed using a handheld analyzer (Lactate Plus, Nova Biomedical, Waltham, Massachusetts, USA). The finger was cleaned with an alcohol swab, and a damp cotton pad removed excess alcohol. The finger was dried for $1 \mathrm{~min}$, after which the treadmill was stopped and the participant's finger was pricked with a lancet. Heart rate (HR) was recorded with a chest strap monitor (Polar, Kempele, Finland).

\section{Psychometric outcomes}

The Feeling Scale (FS), an 11-point scale ranging from +5 to -5 , assessed pleasure and displeasure (Hardy \& Rejeski, 1989). To assess GI distress, a 7-point scale with anchors ranging from "no discomfort" at 1 to "very severe discomfort" at 7 was adapted from the validated Gastrointestinal Symptom Rating Scale (Revicki et al., 1998). Nausea, belching/regurgitation/reflux, bloating/fullness, gas/flatulence, lower abdominal cramps, and urge to defecate were assessed. To assess blinding, participants rated beverage sweetness and overall likability on a labeled hedonic scale (LHS; Lim et al., 2009). Sweetness scores ranged from 0 to +100 ("neutral" to "most sweet sensation imaginable") while overall likability ranged from -100 to +100 ("most disliked sensation imaginable" to "most liked sensation imaginable").

\section{Submaximal protocol}

Constant-velocity, 120-min runs were separated by at least 14 days. A median of 23 (15-33) days elapsed between runs for men, while women completed runs within 26-29 days to control for menstrual cycle. Participants reported to HSPL between 6 and 9 a.m. for their first run and within $1 \mathrm{~h}$ of that time for their second run. Upon arrival, participants voided and were weighed.

Participants' GI symptoms, FS ratings, and HR were recorded 25 min before starting the submaximal protocol. Ten minutes before, participants completed a 5-min warm-up, after which they rested for $5 \mathrm{~min}$. Treadmill velocity for the submaximal protocol was set at $90 \%$ of the average pace from the participant's most recent marathon.

At 25 min before the start, participants consumed their first beverage dose supplying $55.4 \mathrm{~g}$ of carbohydrate $(\sim 600 \mathrm{~mL})$. This pre-exercise feeding was given so that modest boluses could be used during running, as large boluses (200-250 mL every 15-20 min) would have been required to supply carbohydrate at $1.3 \mathrm{~g} /$ min with the exclusive use of during-exercise feedings. Notably, runners reported during pilot testing that they were not accustomed to consuming large fluid boluses $(200-250 \mathrm{~mL})$. Participants consumed additional doses after 20,40,60, 80, and $100 \mathrm{~min}$ of running, and immediately after the submaximal protocol. Feedings at $20,40,60$, and 80 min provided $18.4 \mathrm{~g}$ of carbohydrate $(\sim 180 \mathrm{~mL})$ while feedings at $100 \mathrm{~min}$ and the finish provided 14.7 $(\sim 140 \mathrm{~mL})$ and $11 \mathrm{~g}(\sim 110 \mathrm{~mL})$, respectively. Volumes decreased over time because it was the most tolerable strategy during pilot testing. Treadmill velocity was slowed to $75 \%$ of marathon pace for up to 2 min while participants consumed boluses. Beverages were kept at $2.8-4.0^{\circ} \mathrm{C}$ until $15 \mathrm{~min}$ before the first bolus. The weight of remaining beverage was recorded immediately after the last dose was administered, with a consumption goal of $1682 \mathrm{~g}$.

At specified intervals, respiratory gases (5, 91, $117 \mathrm{~min}), \mathrm{HR} / \mathrm{FS} /$ GI symptoms $(-25,10,30,50,70,90,110 \mathrm{~min})$, and LHS ratings ( -25 , $20,60,100 \mathrm{~min}$ ) were collected. Lactate was taken at 55 and $115 \mathrm{~min}$. A fan was placed adjacent to the treadmill and set at medium velocity. Treadmill velocity was verified every 2 weeks with a tachometer (RPM33, Extech Instruments, Nashua, New Hampshire, USA).

\section{Time trial performance}

After the 120 min submaximal protocol, the treadmill was stopped for $2 \mathrm{~min}$ to allow participants to consume the last beverage dose, allow participants to void, and repeat instructions. Participants were instructed to complete 4 miles as fast as possible and were told they could change velocity as frequently as desired. As GI symptoms are purported to be a mechanism responsible for performance benefits with MTC, participants were told they could use the restroom, if necessary, but that it would count toward finishing time (as it would in a race). The restroom was located in proximity to the treadmill ( $\sim 15 \mathrm{ft}$ ). Participants were unable to view time elapsed but were able to see distance covered. Investigator and participant interactions were limited to soliciting FS and GI ratings. FS ratings and HR were recorded at miles $0.5,1.5,2.5,3.5$, and 4. GI symptoms were solicited at miles 0.5 and 3.5 .

\section{Statistical analyses}

A magnitude-based inferential statistics approach that reports uncertainty of outcomes as $90 \%$ confidence limits (CL) was utilized to evaluate treatment effects. This approach calculates effects with 90\% CL and interprets them in relation to the smallest worthwhile effect (Batterham \& Hopkins, 2006). Interpretation is done using probabilities that the true (population) effect is greater, trivial, or lower in relation to the smallest worthwhile effect. Effects, 90\% CL, and chances that effects were positive, trivial, or negative were calculated using a spreadsheet for crossover trials (Hopkins, 2006b). The smallest worthwhile effects for performance were set at $+0.8 \%$ and $-0.8 \%$, using the recommendation of 0.3 times the coefficient of variation $(\sim 2.5 \%)$ for endurance running performance (Hopkins \& Hewson, 2001; Hopkins, 2004). For physiological measures, GI distress, and FS ratings, differences were interpreted using a Cohen effect, with thresholds set at +0.2 and -.02 (Cohen, 1988). Chance thresholds for variables were accompanied by qualitative descriptors: $<0.5 \%$, almost certainly not; $0.5-5 \%$, very unlikely; $5-25 \%$, unlikely; $25-75 \%$, possibly; 75-95\%, likely; 95-99.5\%, very likely; $>99.5 \%$, almost certain. If chances of positive and negative effects were both $>5 \%$, the effect was considered unclear.

Performance times and physiological measures were natural log transformed (Hopkins, 2003), and performance times were back transformed to obtain percentage differences. Peak GI and LHS 
ratings were percentile rank transformed because of resistance to log transformation. Nadir (low) and change (rest - $110 \mathrm{~min}$ ) FS ratings were used for the submaximal protocol to limit the number of inferences. To account for order or learning effects, differences in finishing time ( $G$ minus GF) were analyzed separately based on randomization sequence $(\mathrm{G} / \mathrm{GF}$ and $\mathrm{GF} / \mathrm{G})$. The independent effects were then combined using a spreadsheet that accounts for order effects (Hopkins, 2006a).

TT data for two participants were excluded. One participant experienced hip pain preventing running during the latter half of his second TT, whereas a treadmill malfunction occurred during another participant's second TT. Additionally, one participant's first TT value was truncated to a value equal to two standard deviations from the mean because it appeared to be a possible outlier, thus preserving the order of the data but reducing the influence of the data point (Field, 2009). Gas exchange for one participant was unavailable because of a computer malfunction. Lactate values were not available for two participants at $55 \mathrm{~min}$ and five participants at $115 \mathrm{~min}$ because of inadequate sample volume, which occurs for up to $10 \%$ of Lactate Plus readings. To simplify interpretation, untransformed means ( \pm standard errors) are presented for variables that were transformed for inferences. Normality was assessed via the Shapiro-Wilk test. Descriptive statistics were generated using SPSS version 22 (IBM, Armonk, New York, USA).

\section{Results}

Randomization was counterbalanced among study completers, with 10 participants randomized to G first and 10 participants to GF first. Intakes of energy (5319 \pm 256 vs $5300 \pm 204 \mathrm{kcal})$, carbohydrate (11 \pm 0.5 vs $10.9 \pm 0.4 \mathrm{~g} / \mathrm{kg}$ body mass), fat (159 \pm 11 vs $155 \pm 12 \mathrm{~g}$ ) and protein (208 \pm 14 vs $223 \pm 17 \mathrm{~g}$ ) were similar for $\mathrm{G}$ and GF over 2 days before the runs.

Finishing times for the TT ranged from 23:50 to $35: 37$ min, and finishing times for $G$ and GF were 28:46 \pm 0:44 and 28:11 $\pm 0: 44 \mathrm{~min}$ (Table 1). Participants completed the TT $1.9 \%(-1.9 ;-4.2,0.4)$ faster with GF compared with $G$, and there was $79 \%$ chance that the true population effect was $-0.8 \%$ or lower. The effect was similar after accounting for order effects $(-2.2 \% ;-4.3,-0.1)$. Effect sizes for men and women were $-1.6 \%(-4.2,1.2)$ and $-2.6 \%(-8.1,3.1)$, respectively.

Participants exercised, on average, at $65 \%$ of $\mathrm{VO}_{2 \text { peak }}$ during the submaximal protocols. Mean oxygen uptake during $\mathrm{G}$ was $2.64 \pm 0.1 \mathrm{~L} / \mathrm{min}$ for all time points, while values during GF were $2.68 \pm 0.1,2.67 \pm 0.1$, and $2.68 \pm 0.1 \mathrm{~L} / \mathrm{min}$ at 5,91 , and $117 \mathrm{~min}$, respectively. Table 2 presents data for physiological variables hypothesized to be different between conditions. Median (IQR) lactate concentrations at $55 \mathrm{~min}$ were 2.3 (1.6-3.4) and 1.9 (1.4-3.3) mmol/L for G and GF. Lactate concentrations were 1.9 (1.3-2.7) and 1.7 (1.4-3.0) $\mathrm{mmol} / \mathrm{L}$ for $\mathrm{G}$ and GF at 115 min. Mean HR over the submaximal protocol was $145.4 \pm 2.3$ and $144.8 \pm 2.1 \mathrm{~b} / \mathrm{min}$ for $\mathrm{G}$ and GF. During the TT, mean HR was $167.9 \pm 2.6$ and 168.3 $\pm 2.5 \mathrm{~b} / \mathrm{min}$ for $\mathrm{G}$ and $\mathrm{GF}$.

Contrary to our hypothesis, carbohydrate oxidation was not higher with GF at the end of the submaximal protocol. In fact, there was a $32 \%$ chance that carbohydrate oxidation was lower with GF. At both 5 and $117 \mathrm{~min}, \mathrm{GF}$ resulted

Table 1. Inferential statistics for 4-mile time trial performance

\begin{tabular}{|c|c|c|c|c|c|}
\hline & $\mathrm{G} \dagger$ & GF† & \% Difference $(90 \% \mathrm{CL}) \neq$ & $\begin{array}{l}\text { Chances of GF being higher, } \\
\text { trivial, and lower relative to Gई }\end{array}$ & Interpretation \\
\hline Finishing time* (min:s) & $28: 46$ & $28: 11$ & $-1.9(-4.2,0.4)$ & $3 \%, 18 \%, 79 \%$ & Likely lower \\
\hline \multicolumn{6}{|c|}{$\begin{array}{l}\text { * Excludes two participants because of a treadmill malfunction and hip pain }(n=18) \text {. } \\
\text { † Means (min:s) prior to transformation } \\
\text { † Based on natural log transformation } \\
\S \text { Based on smallest worthwhile differences of }+0.8 \% \text { and }-0.8 \% \\
\text { CL, confidence limits; } G \text {, glucose-only; GF, glucose-fructose }\end{array}$} \\
\hline & $G^{*}$ & GF* & $\begin{array}{r}\text { Difference expressed } \\
\text { as Cohen }(90 \% \mathrm{CL}) \dagger\end{array}$ & $\begin{array}{l}\text { Chances of GF being higher, } \\
\text { trivial, and lower relative to G‡ }\end{array}$ & Interpretation \\
\hline \multicolumn{6}{|l|}{ CHO oxidation (g/min) } \\
\hline $5 \mathrm{~min}$ & 2.41 & 2.32 & $-0.19(-0.44,0.07)$ & $1 \%, 52 \%, 47 \%$ & Possibly lower \\
\hline $91 \mathrm{~min}$ & 2.05 & 2.08 & $0.06(-0.16,0.28)$ & $13 \%, 84 \%, 3 \%$ & Likely trivial \\
\hline $117 \mathrm{~min}$ & 1.91 & 1.83 & $-0.14(-0.36,0.08)$ & $1 \%, 68 \%, 32 \%$ & Possibly lower \\
\hline \multicolumn{6}{|l|}{ Fat oxidation (g/min) } \\
\hline $5 \mathrm{~min}$ & 0.34 & 0.40 & $0.33(-0.15,0.80)$ & $67 \%, 29 \%, 4 \%$ & Possibly higher \\
\hline $91 \mathrm{~min}$ & 0.49 & 0.49 & $-0.04(-0.36,0.28)$ & $10 \%, 70 \%, 20 \%$ & Unclear \\
\hline $117 \mathrm{~min}$ & 0.54 & 0.60 & $0.18(-0.05,0.41)$ & $45 \%, 55 \%, 0 \%$ & Possibly higher \\
\hline \multicolumn{6}{|l|}{ Lactate (mmol/L) } \\
\hline $55 \min$ & 2.68 & 2.39 & $-0.19(-0.63,0.25)$ & $7 \%, 44 \%, 49 \%$ & Unclear \\
\hline $115 \min$ & 2.07 & 2.12 & $-0.02(-0.50,0.45)$ & $21 \%, 53 \%, 26 \%$ & Unclear \\
\hline
\end{tabular}

* Means prior to transformation

$\dagger$ Based on natural log-transformation

‡ Based on Cohen effect sizes of +0.2 and -0.2. $\mathrm{CHO}$ and fat oxidation unavailable for one participant $(n=19)$. Lactate unavailable for two participants at $55 \mathrm{~min}(n=18)$ and five participants at $115 \mathrm{~min}(n=15)$

CHO, carbohydrate; CL, confidence limits; G, glucose-only; GF, glucose-fructose 
in possibly higher fat oxidation relative to G. Lactate effects were unclear at both time points.

GI distress incidence is shown in Table 3, expressed as frequencies of experiencing any symptoms $(>1)$ and at least mild symptoms $(\geq 3)$. Table 4 shows inferential statistics for
GI symptoms and other psychometric variables. During the submaximal period, belching/regurgitation/reflux, bloating/fullness, and gas/flatulence were all likely lower with GF (Cohen's ranging from -0.37 to -0.45 ), while effects for $a b-$ dominal cramps and urge to defecate were unclear. Similar

Table 3. Incidence of gastrointestinal distress

\begin{tabular}{|c|c|c|c|c|}
\hline & \multicolumn{2}{|c|}{ No. reporting > 1 (\%) } & \multicolumn{2}{|c|}{ No. reporting $\geq 3(\%)$} \\
\hline & G & GF & G & GF \\
\hline \multicolumn{5}{|l|}{ Submaximal $(n=20)$} \\
\hline Nausea & $3(15 \%)$ & $1(5 \%)$ & $1(5 \%)$ & $1(5 \%)$ \\
\hline Belching/regurgitation/reflux & $13(65 \%)$ & $9(45 \%)$ & $2(10 \%)$ & $1(5 \%)$ \\
\hline Fullness/bloating & $14(70 \%)$ & $10(50 \%)$ & $6(30 \%)$ & $3(15 \%)$ \\
\hline Lower abdominal cramps & $9(45 \%)$ & $8(40 \%)$ & $3(15 \%)$ & $1(5 \%)$ \\
\hline Gas/flatulence & $7(35 \%)$ & $4(20 \%)$ & $3(15 \%)$ & $0(0 \%)$ \\
\hline Urge to defecate & $4(20 \%)$ & $3(15 \%)$ & $3(15 \%)$ & $0(0 \%)$ \\
\hline \multicolumn{5}{|l|}{ Time trial $(n=18)$} \\
\hline Nausea & $4(22 \%)$ & $1(6 \%)$ & $1(6 \%)$ & $1(6 \%)$ \\
\hline Belching/regurgitation/reflux & $4(22 \%)$ & $4(22 \%)$ & $0(0 \%)$ & $0(0 \%)$ \\
\hline Fullness/bloating & $5(28 \%)$ & $4(22 \%)$ & $3(17 \%)$ & $1(6 \%)$ \\
\hline Lower abdominal cramps & $7(39 \%)$ & $5(28 \%)$ & $3(17 \%)$ & $3(17 \%)$ \\
\hline Gas/flatulence & $5(28 \%)$ & $4(22 \%)$ & $2(11 \%)$ & $1(6 \%)$ \\
\hline Urge to defecate & $4(22 \%)$ & $2(11 \%)$ & $3(17 \%)$ & $1(6 \%)$ \\
\hline
\end{tabular}

Gl symptoms rated from "no discomfort" = 1 to "very severe discomfort" = 7. Based on peak values reported.

$\mathrm{G}$, glucose-only; GF, glucose-fructose.

Table 4. Inferential statistics for psychometric scales

\begin{tabular}{|c|c|c|c|c|c|}
\hline & $G^{*}$ & GF* & $\begin{array}{r}\text { Difference expressed } \\
\text { as Cohen }(90 \% \mathrm{CL}) \dagger\end{array}$ & $\begin{array}{l}\text { Chances of GF being higher, } \\
\text { trivial, and lower relative to G }\end{array}$ & Interpretation \\
\hline \multicolumn{6}{|l|}{$\mathrm{FS}(-5$ to +5$)$} \\
\hline Submax nadir & 2.15 & 2.55 & $0.22(-0.05,0.49)$ & $55 \%, 44 \%, 1 \%$ & Possibly higher \\
\hline Change (rest - $110 \mathrm{~min}$ ) & 2.35 & 1.90 & $-0.25(-0.49,-0.01)$ & $0 \%, 35 \%, 65 \%$ & Possibly lower \\
\hline TT average & -0.06 & 0.32 & $0.15(-0.17,0.48)$ & $40 \%, 56 \%, 4 \%$ & Possibly higher \\
\hline \multicolumn{6}{|l|}{ Submaximal GI symptoms§ ( 1 to 7 ) } \\
\hline Belching/regurgitation/reflux & 1.75 & 1.50 & $-0.38(-0.81,0.04)$ & $1 \%, 22 \%, 77 \%$ & Likely lower \\
\hline Bloating/fullness & 2.20 & 1.70 & $-0.45(-0.79,-0.10)$ & $0 \%, 11 \%, 89 \%$ & Likely lower \\
\hline Abdominal cramps & 1.60 & 1.50 & $-0.16(-0.55,0.23)$ & $6 \%, 50 \%, 43 \%$ & Unclear \\
\hline Gas/flatulence & 1.50 & 1.20 & $-0.37(-0.78,0.04)$ & $1 \%, 22 \%, 76 \%$ & Likely lower \\
\hline Urge to defecate & 1.35 & 1.15 & $-0.16(-0.54,0.21)$ & $6 \%, 51 \%, 43 \%$ & Unclear \\
\hline \multicolumn{6}{|l|}{ Time trial Gl symptoms ( 1 to 7 ) } \\
\hline Nausea & 1.28 & 1.11 & $-0.44(-1.01,0.14)$ & $4 \%, 21 \%, 76 \%$ & Likely lower \\
\hline Belching/regurgitation/reflux & 1.22 & 1.22 & $0.00(-0.55,0.55)$ & $27 \%, 46 \%, 27 \%$ & Unclear \\
\hline Bloating/fullness & 1.67 & 1.33 & $-0.16(-0.52,0.20)$ & $5 \%, 52 \%, 43 \%$ & Possibly lower \\
\hline Abdominal cramps & 1.72 & 1.56 & $-0.20(-0.56,0.16)$ & $4 \%, 47 \%, 50 \%$ & Possibly lower \\
\hline Gas/flatulence & 1.50 & 1.33 & $-0.14(-0.60,0.33)$ & $11 \%, 48 \%, 41 \%$ & Unclear \\
\hline Urge to defecate & 1.67 & 1.22 & $-0.29(-0.78,0.19)$ & $5 \%, 32 \%, 63 \%$ & Possibly lower \\
\hline \multicolumn{6}{|l|}{ LHS ratings (o to 100) } \\
\hline Sweet rest & 25.1 & 24.0 & $-0.08(-0.48,0.31)$ & $12 \%, 58 \%, 30 \%$ & Unclear \\
\hline Sweet $20 \mathrm{~min}$ & 22.8 & 27.1 & $0.23(-0.16,0.63)$ & $56 \%, 41 \%, 4 \%$ & Possibly higher \\
\hline Sweet $60 \mathrm{~min}$ & 26.4 & $24 \cdot 3$ & $-0.12(-0.44,0.21)$ & $6 \%, 62 \%, 33 \%$ & Unclear \\
\hline Sweet $100 \mathrm{~min}$ & 21.8 & 22.4 & $0.07(-0.39,0.53)$ & $32 \%, 52 \%, 16 \%$ & Unclear \\
\hline Likability rest & 12.0 & 10.8 & $-0.11(-0.46,0.24)$ & $7 \%, 59 \%, 33 \%$ & Unclear \\
\hline Likability 20 min & 16.0 & 15.1 & $-0.04(-0.33,0.25)$ & $8 \%, 74 \%, 18 \%$ & Unclear \\
\hline Likability 60 min & 16.3 & 18.6 & $0.04(-0.32,0.39)$ & $22 \%, 65 \%, 13 \%$ & Unclear \\
\hline Likability 100 min & $13 \cdot 7$ & 21.3 & $0.30(-0.02,0.61)$ & $69 \%, 30 \%, 1 \%$ & Possibly higher \\
\hline
\end{tabular}

* Means prior to transformation

† LHS ratings and peak GI symptoms were based on percentile rank transformation.

‡ Based on smallest worthwhile Cohen effect sizes of +0.2 and -0.2

$\S$ Submaximal nausea was not examined because of low overall incidence. Submaximal, $n=20 ; T T, n=18$

CL, confidence limits; FS, Feeling Scale; G, glucose-only; GF, glucose-fructose; GI, gastrointestinal; LHS, labeled hedonic scale; TT, time trial 
patterns for GI distress emerged during the TT, but effect sizes were generally smaller. Relative to a Cohen threshold of 0.2 , nadir FS ratings during the submaximal protocol were possibly higher with GF ( $55 \%$ chance), and FS ratings possibly showed a smaller reduction from rest to 110 min (65\% chance). FS ratings averaged over the TT were possibly higher with GF ( $40 \%$ chance). Effects for beverage sweetness and likability were unclear, with the exception of possibly higher sweetness with GF at $20 \mathrm{~min}$ (Cohen $=0.23$; $-0.16,0.63$ ) and higher likability with GF at $100 \mathrm{~min}$ (Cohen $=0.30 ;-0.02,0.61$ ).

Weights of beverage consumed for G and GF were 1660 $\pm 2 \mathrm{~g}$ and $1659 \pm 2 \mathrm{~g}$, respectively. Body weight decreased by $1.8 \pm 0.1 \mathrm{~kg}$ for both conditions.

\section{Discussion}

The primary finding of this investigation was that ingestion of a glucose-fructose beverage (ratio of 1.2:1) likely improved 4-mile TT performance after $2 \mathrm{~h}$ of submaximal running. This finding should be interpreted within the context of the study design, with factors including a carbohydrate feeding rate of $1.3 \mathrm{~g} / \mathrm{min}$, a carbohydrate concentration of $10 \%$, and exercise intensity of $60-70 \% \mathrm{VO}_{2 \text { peak }}$. In addition, participants completed trials in a fed state, which increases the generalizability of findings relative to previous studies (Jeukendrup \& Moseley, 2010; Lecoultre et al., 2010; Triplett et al., 2010; O’Brien \& Rowlands, 2011; Roberts et al., 2014). The direction and magnitude of performance benefits were similar for men and women, with magnitudes ranging from $1.6 \%$ to $2.6 \%$.

Notably, this is the first study to find a likely performance benefit with MTC during running. Previously, Pfeiffer et al. (2009) and Lee et al. (2014) examined the effects of glucoseonly or glucose-fructose ingestion on endurance running performance. In Pfeiffer et al. (2009), gels supplied carbohydrate at $1.4 \mathrm{~g} / \mathrm{min}$ during $16 \mathrm{~km}$ outdoor running, and finishing times were not different between conditions $(1: 14: 25$ for glucose vs 1:14:41 for glucose-fructose). Lee et al. (2014) utilized half-marathon treadmill running, and carbohydrate was supplied at roughly $1.0 \mathrm{~g} / \mathrm{min}$ in three forms $(6 \%$ glucose-only beverage, glucose-only gels, and glucose-fructose gels). No significant perceptual or performance differences were found, although effect sizes between the conditions were modest (glucose-fructose gel resulted in 2.7-3.0\% slower finishing times). The fact that our study used a protocol of sustainably longer duration may partly explain the discrepant findings with these two studies. The other running-based study had 11 men complete a 90 -min soccer protocol while ingesting carbohydrate at $1.0 \mathrm{~g} / \mathrm{min}$ from glucose or a 2:1 glucose-fructose mix (Clarke et al., 2012). After the protocol, participants ran to exhaustion on a treadmill at $12.8 \mathrm{~km} / \mathrm{h}$ and $20 \%$ grade. Time-to-exhaustion $(83 \pm 3$ vs $77 \pm 7.2 \mathrm{~s}$ ) was not significantly different, but there was a trend for longer time-to-exhaustion with glucose-fructose
$(P=0.06)$. Given the inconsistencies between studies, further research is needed to delineate the effects of MTC for a range of running-based tasks.

The GI effects of fructose may partly explain the performance benefit in this study, as previous investigations indicate that GI distress can negatively impact performance. Rowlands et al. (2012) and O'Brien et al. (2013) used statistical modeling to assess the magnitude of performance benefit attributable to reductions in GI symptoms and found that abdominal cramps significantly mediated cycling performance outcomes. Moreover, one of the only MTC studies to utilize a pure TT clearly showed that GI distress can substantially impair performance. Specifically, participants finished a $100-\mathrm{km}$ cycle TT $8 \%$ faster when consuming a glucose-fructose beverage compared with glucose-only, and of nine participants, two experienced diarrhea and one experienced vomiting with glucose-only (Triplett et al., 2010). These observations seem to be supported by our data, as GI distress was possibly-to-likely lower with GF for most symptoms.

Several mechanisms may be responsible for the observed GI effects. Under resting conditions, concentrated fructosecontaining solutions empty faster from the stomach than glucose solutions (Sole \& Noakes, 1989), and these differences are best explained by the inhibitory feedback effects of glucose on intestinal afferents (Zittel et al., 1994). Inhibition of gastric emptying with glucose would explain the likely higher ratings of bloating/fullness observed with G during the present study. Additionally, SGLT1 transporters may become saturated with large, rapid glucose feedings, which could cause carbohydrate malabsorption and osmotic fluid shifts into the intestine (Jeukendrup, 2010). These effects could explain the possibly higher ratings of abdominal cramping and gas in this and previous studies.

In terms of psychological affect, it is possible the GF resulted in higher FS ratings. These positive effects were apparent when expressing FS ratings as nadir and change values, as well as average values during the TT. In light of the multiple physiological effects of fructose, we are not able to delineate precisely which mechanisms were responsible for the possible differences. Interestingly, a recent blinded study found that glucose and fructose activate different brain regions and may have differential effects on reward and motivational processing (Page et al., 2013). Others have argued that sweetness partially mediates the performance benefit of glucose-fructose ingestion (O'Brien et al., 2013), but sweetness differences were not generally apparent in this study (with the exception of a small possible difference at $20 \mathrm{~min}$ ). Beverage likability was similar between conditions, but ratings for GF were likely higher at 100 min despite no differences in sweetness. It will be important for future studies to assess beverage sensory characteristics in order to help delineate whether metabolic or psychometric properties of fructose are primarily responsible for performance benefits with MTC ingestion. 
Despite the apparent confirmation of performance, GI, and psychological benefits, our hypotheses that glucosefructose would result in higher lactate and carbohydrate oxidation were not supported. Previous studies found higher lactate concentrations with fructose feeding compared with glucose, but timing of ingestion may mediate this effect. Fructose ingestion prior to exercise elevates blood lactate during the postprandial period, but lactate falls with the onset of exercise, at least in comparison to glucose (Hargreaves et al., 1985). Thus, feeding a substantial amount of fructose $25 \mathrm{~min}$ prior to exercise possibly minimized elevations in lactate 80 min later. In regards to carbohydrate oxidation, some (Lecoultre et al., 2010; Roberts et al., 2014) but not all studies (Jeukendrup \& Moseley, 2010) have found differences in total carbohydrate oxidation with MTC. Interestingly, fat oxidation was possibly higher for GF at 5 and 117 min. Lower fat oxidation with G, especially at $5 \mathrm{~min}$, could have been due to a greater insulin release, leading to insulinassociated fat oxidation suppression (Koivisto et al., 1981). Given the lack of support for our hypotheses related to carbohydrate and lactate metabolism, it would seem the performance benefits were more likely a result of GI and psychological effects.

There are several novel approaches and strengths to this study. Unlike much of the previous literature, this investigation was double-blinded with data on participant blinding. The majority of previous studies were conducted with participants fasted, but participants in our study received two meals to ensure nutrition was similar between participants and trials. Furthermore, the beverage volume was similar to intakes observed in the field (Pfeiffer et al., 2012), and since many of the previous investigations used volumes $(\sim 1000$ $\mathrm{mL} / \mathrm{h}$ ) exceeding ad libitum intakes, generalizability of previous data may be limited.

Despite this study's strengths, limitations need to be acknowledged. We did not use a non-carbohydrate control, mainly because participant burden would have been increased to three runs. Recruitment was likely enhanced, however, by requiring only two runs, which was evidenced by the relatively large sample size. Another limitation is the lack of data on exogenous carbohydrate oxidation, which requires tracers; the use of invasive and time-consuming testing was avoided to maximize recruitment. Finally, the amount of fluid and carbohydrate ingested were not according to participant preference. Competitors that experience GI distress often adjust intake to mitigate symptoms, but our participants were required to drink a prescribed rate regardless of symptoms experienced.

\section{Perspectives}

This study showed that ingestion of glucose-fructose in a ratio of 1.2:1 - compared with glucose-only - likely improved performance, possibly reduced GI distress, and possibly improved psychological affect during prolonged running. The performance benefits observed were most likely attributable to GI and psychological effects of glucose-fructose co-ingestion. These results apply to competitive runners consuming fluid and carbohydrate at relatively aggressive rates $(500-600 \mathrm{~mL} / \mathrm{h}$ and $1.0-1.3 \mathrm{~g} / \mathrm{min})$ during running at an intensity of $60-70 \% \mathrm{VO}_{2 \text { peak }}$. Performance benefits were similar for men and women alike, and thus, this study provides evidence - albeit tentative - that ingestion of MTC can be useful for female athletes. To build upon these findings, additional studies are needed to determine whether MTC improve performance, GI distress, and psychological affect for a wide range of running-based activities.

Acknowledgments - The authors thank the athletes who participated in this research. Mark Pereira and Beth Lewis deserve thanks for their review and thoughtful comments. We are grateful to Tate \& Lyle Ingredients Americas, Ingredion, and NutraSweet for donating the beverage ingredients.

Funding - This study was funded in part by the University of Minnesota Doctoral Dissertation Fellowship and Hauge Fellowship.

\section{References}

Batterham AM, Hopkins WG. Making meaningful inferences about magnitudes. Int J Sports Physiol Perform 2006: 1 (1): 50-57.

Clarke ND, Campbell IT, Drust B, Evans L, Reilly T, Maclaren DP. The ingestion of combined carbohydrates does not alter metabolic responses or performance capacity during soccer-specific exercise in the heat compared to ingestion of a single carbohydrate. J Sports Sci 2012: 30 (7): 699-708.

Cohen J. Statistical power analysis for the behavioral sciences. 2nd edn. Hillsdale, NJ: Lawrence Erlbaum Associates, 1988. 20 p.

Field A. Discovering statistics using SPSS. 3rd edn. London: Sage, 2009. 153 p.

Hardy CJ, Rejeski W. Not what, but how ones feels: the measurement of affect during exercise. J Sport Exerc Psychol 1989: 11 (3): 304-317.

Hargreaves M, Costill DL, Katz A, Fink WJ. Effect of fructose ingestion on muscle glycogen usage during exercise. Med Sci Sports Exerc 1985: 17 (3): 360-363.

Hopkins WG. A spreadsheet for analysis of straightforward controlled trials. Sportscience. 2003: 7: Online: http://www. sportsci.org/jour/03/wghtrials.htm (accessed April 6, 2014).

Hopkins WG. How to interpret changes in an athletic performance test. Sportscience 2004: 8: 1-7. Online: http://www.sportsci. org/jour/04/wghtests.htm (accessed April 6, 2014).

Hopkins WG. A spreadsheet for combining outcomes from several subject groups. Sportscience 2006a: 10: 51-53. Online: http://www.sportsci.org/2006/wghcom.htm (accessed April $15,2014)$.

Hopkins WG. Spreadsheets for analysis of controlled trials, with adjustment for a subject characteristic. Sportscience 2006b: 10: 46-50. Online: http://www.sportsci.org/2006/wghcontrial.htm (accessed April 6, 2014).

Hopkins WG, Hewson DJ. Variability of competitive performance of distance runners. Med Sci Sports Exerc 2001: 33 (9): 1588-1592. 
Jeukendrup AE. Carbohydrate and exercise performance: The role of multiple transportable carbohydrates. Curr Opin Clin Nutr Metab Care 2010: 13 (4): 452-457.

Jeukendrup AE, Moseley L. Multiple transportable carbohydrates enhance gastric emptying and fluid delivery. Scand J Med Sci Sports 2010: 20 (1): 112-121.

Jeukendrup AE, Wallis GA. Measurement of substrate oxidation during exercise by means of gas exchange measurements. Int J Sports Med 2005: 26 (S1): S28-S37.

Koivisto VA, Karonen SL, Nikkila EA. Carbohydrate ingestion before exercise: comparison of glucose, fructose, and sweet placebo. J Appl Physiol 1981: 51 (4): 783-787.

Lecoultre V, Benoit R, Carrel G, Schutz Y, Millet GP, Tappy L, Schneiter P. Fructose and glucose co-ingestion during prolonged exercise increases lactate and glucose fluxes and oxidation compared with an equimolar intake of glucose. Am J Clin Nutr 2010: 92 (5): 1071-1079.

Lee MJC, Hammond KM, Vasdev A, Poole KL, Impey SG, Close GL, Morton JP. Self-selecting fluid intake while maintaining high carbohydrate availability does not impair half-marathon performance. Int J Sports Med 2014: In press.

Lim J, Wood A, Green BG. Derivation and evaluation of a labeled hedonic scale. Chem Senses 2009: 34 (9): 739-751.

Macdonald I, Keyser A, Pacy D. Some effects, in man, of varying the load of glucose, sucrose, fructose, or sorbitol on various metabolites in blood. Am J Clin Nutr 1978: 31 (8): 1305-1311.

Miller BF, Fattor JA, Jacobs KA, Horning MA, Navazio F, Lindinger MI, Brooks GA. Lactate and glucose interactions during rest and exercise in men: Effect of exogenous lactate infusion. J Physiol 2002: 544 (3): 963-975.

O'Brien WJ, Rowlands DS. Fructose-maltodextrin ratio in a carbohydrate-electrolyte solution differentially affects exogenous carbohydrate oxidation rate, gut comfort, and performance. Am J Physiol Gastrointest Liver Physiol 2011: 300 (1): G181-G189.

O’Brien WJ, Stannard SR, Clarke JA, Rowlands DS. Fructose-maltodextrin ratio governs exogenous and other $\mathrm{CHO}$ oxidation and performance. Med Sci Sports Exerc 2013: 45 (9): 1814-1824.

Page KA, Chan 0, Arora J, Belfort-Deaguiar R, Dzuira J, Roehmholdt B, Cline GW, Naik S, Sinha R, Constable RT, Sherwin RS. Effects of fructose vs glucose on regional cerebral blood flow in brain regions involved with appetite and reward pathways. JAMA 2013: 309 (1): 63-70.

Peters HP, van Schelven FW, Verstappen PA, de Boer RW, Bol E, Erich WB, van der Togt CR, de Vries WR. Gastrointestinal problems as a function of carbohydrate supplements and mode of exercise. Med Sci Sports Exerc 1993: 25 (11): 1211-1224.
Pfeiffer B, Cotterill A, Grathwohl D, Stellingwerff T, Jeukendrup AE. The effect of carbohydrate gels on gastrointestinal tolerance during a 16-km run. Int J Sport Nutr Exerc Metab 2009: 19 (5): 485-503.

Pfeiffer B, Stellingwerff T, Hodgson AB, Randell R, Pöttgen K, Res $P$, Jeukendrup AE. Nutritional intake and gastrointestinal problems during competitive endurance events. Med Sci Sports Exerc 2012: 44 (2): 344-351.

Revicki DA, Wood M, Wiklund I, Crawley J. Reliability and validity of the Gastrointestinal Symptom Rating Scale in patients with gastroesophageal reflux disease. Qual Life Res 1998: 7 (1): 75-83.

Roberts JD, Tarpey MD, Kass LS, Tarpey RJ, Roberts MG. Assessing a commercially available sports drink on exogenous carbohydrate oxidation, fluid delivery and sustained exercise performance. J Int Soc Sports Nutr 2014: 11 (1): 8. Online: http://www.jissn. com/content $/ 11 / 1 / 8$

Rowlands DS, Swift M, Ros M, Green JG. Composite versus single transportable carbohydrate solution enhances race and laboratory cycling performance. Appl Physiol Nutr Metab 2012: 37 (3): 425-436.

Rowlands DS, Thorburn MS, Thorp RM, Broadbent S, Shi X. Effect of graded fructose co-ingestion with maltodextrin on exogenous ${ }^{14} \mathrm{C}$-fructose and ${ }^{13} \mathrm{C}$-glucose oxidation efficiency and highintensity cycling performance. J Appl Physiol 2008: 104 (6): 1709-1719.

Sole CC, Noakes TD. Faster gastric emptying for glucose-polymer and fructose solutions than for glucose in humans. Eur J Appl Physiol Occup Physiol 1989: 58 (6): 605-612.

Triplett D, Doyle JA, Rupp JC, Benardot D. An isocaloric glucosefructose beverage's effect on simulated $100-\mathrm{km}$ cycling performance compared with a glucose-only beverage. Int J Sport Nutr Exerc Metab 2010: 20 (2): 122-131.

U.S. Department of Agriculture. Agricultural Research Service: USDA National Nutrient Database for Standard Reference, 2012. Release 26. Online: http://ndb.nal.usda.gov/ndb/ (accessed March 25, 2014).

Wood IS, Trayhurn P. Glucose transporters (GLUT and SGLT): expanded families of sugar transport proteins. Br J Nutr 2003: 89 (1): 3-9.

Zittel TT, Rothenhofer I, Meyer JH, Raybould HE. Small intestinal capsaicin-sensitive afferents mediate feedback inhibition of gastric emptying in rats. Am J Physiol 1994: 267 (6 Pt 1): G1142-G1145. 